\title{
Disruption of Trichoderma reesei gene encoding protein $O$-mannosyl- transferase $I$ results in a decrease of the enzyme activity and alteration of cell wall composition
}

\author{
Wioletta Górka-Nieć, Michał Pniewski, Anna Kania, Urszula Perlińska-Lenart, \\ Grażyna Palamarczyk and Joanna S. Kruszewska ${ }^{凶}$ \\ Institute of Biochemistry and Biophysics, Polish Academy of Sciences, Warszawa, Poland
}

Received: 01 February, 2008; revised: 14 April, 2008; accepted: 25 April, 2008

available on-line: 26 May, 2008

\begin{abstract}
In fungi transfer of the first mannosyl residue to proteins during their O-glycosylation is catalyzed by protein $O$-mannosyltransferases encoded by $p m t$ genes. Disruption of the $p m t 1$ gene in Trichoderma caused a significant decrease in the total activity of protein $O$-mannosyltransferases. Moreover, disruption of the pmt1 gene also led to osmotic sensitivity of the strain, indicating an essential role of the PMTI protein activity for cell wall synthesis. At the same time, the strain was defective in septa formation, producing only half the number of septa per unit length of hypha compared with the wild type. Disruption of the pmt1 gene decreased protein secretion but had no effect on glycosylation of secreted proteins, which suggests that PMTI protein $O$-mannosyltranferase does not take part in glycosylation of these proteins.
\end{abstract}

Keywords: Trichoderma reesei, pmt1 gene disruption, protein glycosylation, cell wall composition

\section{INTRODUCTION}

Trichoderma species are widely exploited in biotechnology for protein production owing to their exceptional protein synthesis and secretory capability. Our previous study indicated that protein production and secretion could be closely related to the activity of the O-glycosylation pathway (Kruszewska et al., 1999; Perlińska-Lenart et al., 2005; 2006b).

In fungi the direct reaction of O-mannosylation is catalyzed by protein $\mathrm{O}$-mannosyltransferases (EC 2.4.1.109) and consists in transfer of a mannosyl residue from dolichyl phosphate mannose (DPM) to the serine/threonine $\mathrm{OH}$ group of the protein. It is known that in Saccharomyces cerevisiae protein Omannosyltransferases are encoded by seven PMT genes and they are classified in three subfamilies PMT1, PMT2 and PMT4 (Gentzsch \& Tanner, 1996; 1997). Members of the PMT1 and PMT2 subfamilies, Pmt1p, and Pmt5p, and Pmt2p, Pmt3p, and Pmt6, respectively, form enzymaticaly active heterodimers such as Pmt1-Pmt2 and Pmt3-Pmt5. Deletion of a $P M T$ gene encoding a protein from these groups resulted in the formation of less active complexes such as Pmt1-Pmt3 or Pmt2-Pmt5. The PMT4 family has one member only, Pmt4p, and this protein forms an active homodimer. Moreover, protein O-mannosyltransferases are substrate-specific (Gentzsch \& Tanner, 1997).

In yeast, O-glycosylation was shown to be essential for cell wall rigidity and cell integrity. A lack of activity of two (Pmt2p, Pmt3p or Pmt2p, Pmt4p) or three (Pmt1p, Pmt2p, Pmt3p) protein O-mannosyltransferases made the strains unable to grow in normal conditions, however, they could be saved by osmotic stabilization with $1 \mathrm{M}$ sorbitol (Gentzsch \& Tanner, 1996). On the other hand, some other triple deletions of PMT genes such as PMT1, PMT2, PMT4 or PMT2, PMT3, PMT4 could not be rescued by osmotic stabilization (Strahl-Bolsinger et al., 1999).

Corresponding author: Joanna S. Kruszewska, Institute of Biochemistry and Biophysics, Polish Academy of Sciences, A. Pawińskiego 5a, 02-106 Warszawa, Poland; phone: (48 22) 592 1209; fax: (48 22) 658 4636; e-mail: jsk@ibb.waw.pl Abbreviations: DPM, dolichyl phosphate mannose; DTT, dithiotheritol; GDP-mannose, guanosine 5'-diphospho-D-mannose; PMT, protein $O$-mannosyltransferase; PMTI, protein $O$-mannosyltransferase I. 
Since protein $\mathrm{O}$-mannosyltransferases are substratespecific those results suggested that the vital role of protein O-mannosylation is connected with O-mannosylation of some cell wall proteins.

In Schizosaccharomyces pombe the protein $\mathrm{O}$ mannosyltransferase family is not as redundant as in S. cerevisiae and has only three members Oma1p, Oma2p and Oma4p, one in each PMT subfamily (Willer et al., 2005). The oma $1 \Delta$ and oma $4 \Delta$ mutants revealed some changes in their cell wall composition while deletion of the oma2 gene turned out to be lethal (Willer et al., 2005).

Disruption of the pmtA gene in Aspergillus awamori gave a similar cell wall fragile phenotype as observed for yeasts. The disruptant exhibited swollen hyphae formation and increased sensitivity to Congo Red and high temperature (Oka et al., 2005). Analysis of cell wall composition of the mutant revealed a lower content of alkali-insoluble fraction which is believed to be responsible for fungal cell wall rigidity, and simultaneous an increase of chitin level.

Our previous study pointed at a fundamental role of cell wall permeability for protein secretion in Trichoderma (Perlińska-Lenart et al., 2006b). Removal of the cell wall from Trichoderma strains carrying the yeast DPM1 gene, encoding DPM synthase resulted in a four-fold increase of protein secretion compared to mycelia which suggested that the cell wall made a barrier for secretion in these strains. This effect, however, was only observed for DPM1-transformed strains characterized by efficient processing of newly synthesized glycoproteins, but not for the control strain, showing that not only cell wall made a barrier for secretion but also the limited modification of secretory proteins (Perlińska-Lenart et al., 2006b).

Up to now only one pmt gene encoding protein $\mathrm{O}$-mannosyltransferase in Trichoderma has been cloned (NCBI accession number AF526877) (Zakrzewska et al., 2003a). Analysis of the predicted protein sequence of the Trichoderma PMTI protein showed the highest $51 \%$ identity with S. cerevisiae Pmt4p. On the other hand, expression of the Trichoderma PMTI protein in S. cerevisiae pmt mutants revealed its functional similarity to the yeast Pmt2 protein. The Trichoderma PMTI protein was able to form an active O-mannosyltransferase complex with yeast Pmt1p and partially rescued the defective glycosylation pattern of chitinase (Zakrzewska et al., 2003a) and completely restored glycosylation of heterologously expressed cellobiohydrolase II from Trichoderma in the pmt2 $\Delta$ S. cerevisiae mutant (Górka-Nieć et al., 2007).

In this study we presented influence of disruption of the pmt1 gene in $T$. reesei on the glycosylation, production and secretion of proteins and on cell wall composition. The strain carrying pmt1 disruption needed an osmotic stabilizer (e.g. $1 \mathrm{M}$ sorbitol) for growth in liquid medium. On the other hand, it was able to grow on the agar plates, albeit very slowly.

Disruption of the pmt1 gene resulted in a significant decrease in the total activity of protein $O$ mannosyltransferases and caused a decrease of protein secretion but did not alter O- and N-glycosylation of secreted proteins. Since protein O-mannosyltransferases are substrate-specific and the lack of the PMTI activity did not change O-mannosylation of the secretory proteins, we conclude that PMTI does not take part in the O-glycosylation of these proteins.

\section{MATERIALS AND METHODS}

Strains and growth conditions. T. reesei TU-6 (Harman \& Kubicek, 1998) was used as a recipient strain for transformation. Escherichia coli strain JM 109 was used for plasmid propagation (Yanish-Perron et al., 1985). T. reesei was cultivated at $30^{\circ} \mathrm{C}$ on a rotary shaker (250 r.p.m.) in 21 shake flasks containing 11 of minimal medium (MM): $1 \mathrm{~g} \mathrm{MgSO}_{4}$ $\times 7 \mathrm{H}_{2} \mathrm{O}, 6 \mathrm{~g}\left(\mathrm{NH}_{4}\right)_{2} \mathrm{SO}_{4}, 10 \mathrm{~g} \mathrm{K \textrm {K } _ { 2 }} \mathrm{PO}_{4}, 3 \mathrm{~g}$ sodium citrate $\times 2 \mathrm{H}_{2} \mathrm{O}$, and trace elements $\left(25 \mathrm{mg} \mathrm{FeSO}{ }_{4} \times\right.$ $7 \mathrm{H}_{2} \mathrm{O}, 2.7 \mathrm{mg} \mathrm{MnCl} \times 4 \mathrm{H}_{2} \mathrm{O}, 6.2 \mathrm{mg} \mathrm{ZnSO}_{4} \times 7 \mathrm{H}_{2} \mathrm{O}$, $\left.14 \mathrm{mg} \mathrm{CaCl} \times 2 \mathrm{H}_{2} \mathrm{O}\right)$ per liter and $1 \%(\mathrm{w} / \mathrm{v})$ lactose as a carbon source. The flasks were inoculated with $42 \times 10^{6}$ konidia/l medium.

Disruption of the pmt1 gene in $T$. reesei. The plasmid for pmt1 disruption was constructed as follows. DNA fragment of about $4000 \mathrm{bp}$ containing genomic pmt1 (NCBI accession number AY515299) and flanking sequences was amplified from genomic DNA by PCR, using The Expand High Fidelity PCR System (Boehringer, Mannheim) and pmt1-U2 (5' CGC CAG CGA ATG ATT CGA CGG AGG $3^{\prime}$ ) and pmt1-L2 (5' CAA GGT GGC TTC TTG TTG CGA CGA $3^{\prime}$ ) primers. The PCR product was cloned into the pGEM-T Easy Vector (Promega), digested with EcoRI and cloned in pRS316 (NCBI accession number U03442) devoid of SalI restriction site. Next the pmt1 gene was cut with SalI in the middle and the T. reesei pyr4 coding sequence cut out from the PGF1 vector (Gruber et al., 1990) was cloned there. About 6500 bp of DNA was cut out from the resulting plasmid with EcoRI and used for T. reesei TU-6 transformation. The pmt1 disruption in the pyr4+ transformants was confirmed by PCR using Pmt554U ( $5^{\prime}$ TTG GCT GGC TGG TTG GCT ACG AC $\left.3^{\prime}\right)$ and Pmt1730L (5' GCT GGG AGT GAT TTG CTT GTT GC $3^{\prime}$ ) primers. For Southern blot analysis, DNA from disruptants and the parental strain was digested with PvuII and XhoI, loaded onto agarose gel, blotted and hybridized with the $1.8 \mathrm{~kb} P v u \mathrm{II} / \mathrm{XhoI}$ fragment of T. reesei pmt1. Radioactive probe was prepared using $\left[\alpha^{-}{ }^{32} \mathrm{P}\right]$ 
dATP and the Fermentas HexaLabel Plus DNA labeling system according to the standard protocol.

Molecular biology methods. Chromosomal DNA was isolated from T. reesei using the Promega Wizard Genomic DNA Purification kit. Other molecular biology procedures were performed according to standard protocols (Sambrook et al., 1989).

\section{Biochemical methods}

Membrane fraction preparation. Mycelium was harvested by filtration, washed with water and suspended in $50 \mathrm{mM}$ Tris/ $\mathrm{HCl}, \mathrm{pH} 7.4$, containing 15 $\mathrm{mM} \mathrm{MgCl}{ }_{2}$ and $9 \mathrm{mM} \beta$-mercaptoethanol. Cells were homogenized in a beadbeater with glass beads $(0.5$ $\mathrm{mm})$ and the homogenate was centrifuged at 5000 $\times g$ for $10 \mathrm{~min}$ to remove cell debris and unbroken cells. The supernatant was centrifuged at $100000 \times$ $g$ for $1 \mathrm{~h}$. The membrane pellet was homogenized in $50 \mathrm{mM}$ Tris/ $\mathrm{HCl}, \mathrm{pH} 7.4$, containing $3.5 \mathrm{mM} \mathrm{MgCl}_{2}$ and $6 \mathrm{mM} \beta$-mercaptoethanol, and used as the source of enzymes. The whole procedure was performed at $4^{\circ} \mathrm{C}$ (Pless \& Palamarczyk, 1987).

Activity of protein $\mathrm{O}$-mannosyltransferases. Protein $O$-mannosyltransferase activity was assayed in the pelleted membrane fraction by $1 \mathrm{~h}$ incubation at $30^{\circ} \mathrm{C}$ with $\mathrm{GDP}\left[{ }^{14} \mathrm{C}\right]$-mannose (sp. act. 288 $\mathrm{Ci} / \mathrm{mol}$, Amersham) and $5 \mathrm{ng}$ of dolichyl phosphate (Dol-P), according to Kruszewska et al. (1989). Total membrane proteins (about $300 \mu \mathrm{g}$ ) were used as the sugar acceptor. Since only the transfer of the first mannosyl residue from dolichyl phosphate mannose (DPM) to the hydroxyl group of serine or threonine catalyzed by Pmt proteins was to be measured, the reaction mixture was supplemented with $10 \mathrm{mM}$ $\mathrm{MgCl}_{2}$. Under these conditions elongation of the O-linked sugar chain does not occur (Sharma et al., 1974). The protein O-mannosyltransferase activity was expressed in pmoles of $\left[{ }^{14} \mathrm{C}\right]$ mannose incorporated into $1 \mathrm{mg}$ of membrane protein during $1 \mathrm{~h}$.

$\mathrm{N}$-acetylglucosamine transferase activity. $\mathrm{N}$ acetylglucosamine transferase activity was measured in the membrane fraction by $30 \mathrm{~min}$ incubation at $30^{\circ} \mathrm{C}$ of $200 \mu \mathrm{g}$ of membrane proteins in a total volume of $50 \mu \mathrm{l}$ containing $1 \times 10^{5}$ c.p.m. UDP $\left[{ }^{14} \mathrm{C}\right] N$ acetylglucosamine (sp. act. $249 \mathrm{Ci} / \mathrm{mol}$, Amersham) and $5 \mathrm{ng}$ of Dol-P in $40 \mathrm{mM}$ Tris $/ \mathrm{HCl}$ buffer, $\mathrm{pH}$ 7.4, with $10 \mathrm{mM} \mathrm{MgCl}$ and $0.1 \%$ Nonidet P-40 (Palamarczyk \& Hemming, 1975). The reaction was stopped by addition of $4 \mathrm{ml}$ of chloroform/methanol $(3: 2, v / v)$. Formation of radioactive dolichyl diphosphate $\mathrm{N}$-acetylglucosamine and dolichyl diphosphate chitobiose was measured in the organic fraction by a scintillation counter.

Concentration of saccharides bound to secreted proteins. Saccharides bound to proteins isolated from $T$. reesei culture filtrates were assayed by the phenol-sulfuric acid procedure (Dubois et al., 1956). Secreted proteins were precipitated with two volumes of ethanol, washed twice with $70 \%$ ethanol and dissolved in distilled water. O-linked sugars were cleaved by mild alkaline hydrolysis and then remaining proteins containing $\mathrm{N}$-linked sugars were precipitated with two volumes of ethanol and centrifuged. The concentration of O-linked carbohydrates was measured in the supernatant after evaporation of ethanol, and N-linked sugars were assayed in the pellet. A calibration curve was prepared with D-mannose.

Protein concentration assay. Protein concentrations were estimated according to Lowry et al. (1951).

Quantification of fungal dry mass. Fungal dry mass was quantified by filtering culture samples through G1 sintered glass funnels, washing the biomass with a threefold volume of tap water, and drying to constant weight at $110^{\circ} \mathrm{C}$.

Colony growth rate. Colony growth rates were measured as described by Oka et al. (2004). Conidia were point-inoculated into the center of agar MM plates with or without osmotic stabilizers (1 M sorbitol or $0.6 \mathrm{M} \mathrm{KCl})$ or with the antifungal agent Calcofluor white $\left(300 \mu \mathrm{g} \mathrm{ml}^{-1}\right)(\mathrm{Oka}$ et al., 2004) and incubated at $30^{\circ} \mathrm{C}$. Colony diameter was measured at $48,72,96,120$ and $144 \mathrm{~h}$. Measurements of the growth for all strains were done six times.

Cell wall preparation. T. reesei strains were cultivated for $168 \mathrm{~h}$ and the mycelia were harvested by centrifugation, homogenized in a beadbeater with $0.5 \mathrm{~mm}$ glass beads in $50 \mathrm{mM}$ Tris/ $\mathrm{HCl}, \mathrm{pH}$ 7.5, with $1 \mathrm{mM}$ DTT and centrifuged at $1500 \times g$ for $10 \mathrm{~min}$.

The resulting pellet containing cell walls was washed with ice-cold $1 \mathrm{M} \mathrm{NaCl}$ until disappearance of absorbance at 260-280 nm (Nemcovic \& Farkas, 2001).

Determination of cell wall polysaccharides. The amount of glucans in the cell wall was determined as described previously (Oka et al., 2004), with a slight modification. For quantification of alkali-soluble $\beta$ - $(1,6)$ glucan, $200 \mathrm{mg}$ of cell walls was suspended in $3 \% \mathrm{NaOH}$, heated at $75^{\circ} \mathrm{C}$ for $1 \mathrm{~h}$ and centrifuged. The supernatant was dialyzed overnight at $4^{\circ} \mathrm{C}$ against distilled water, lyophilized and the amount of alkali-soluble $\beta-(1,6)$ glucan was estimated by the method described by Dubois et al. (1956). The remaining pellet was washed twice with $0.1 \mathrm{M}$ Tris/ $\mathrm{HCl}, \mathrm{pH} 7.4$, and once with $10 \mathrm{mM}$ Tris/ $\mathrm{HCl}$, $\mathrm{pH} 7.4$, and digested overnight with zymolyase 20T (ICN Biomedicals Inc.) $(5 \mathrm{mg} / \mathrm{ml}$ in $10 \mathrm{mM}$ Tris/HCl $\mathrm{pH}$ 7.4). Then the samples were centrifuged (13000 r.p.m., $15 \mathrm{~min}$ ) and the supernatant was used to estimate the amount of alkali-insoluble $\beta$ - $(1,3)$ glucan by the same method (Dubois et al., 1956). The remaining pellets were incubated for $16 \mathrm{~h}$ with $70 \%$ sulfu- 
ric acid at $4^{\circ} \mathrm{C}$, then diluted ten-fold with water and heated at $100^{\circ} \mathrm{C}$ for $8 \mathrm{~h}$. After neutralization with 2 $\mathrm{M} \mathrm{NaOH}$ samples were used to estimate the amount of alkali-insoluble $\beta-(1,6)$ glucan (Dubois et al., 1956).

For chitin measurements alkaline hydrolysis of cell walls was performed in $6 \% \mathrm{KOH}$ for $90 \mathrm{~min}$ at $80^{\circ} \mathrm{C}$ in order to release cell wall proteins. After neutralization with acetic acid, the cell walls were washed with phosphate-buffered saline and chitinase buffer, $\mathrm{pH}$ 6.0, containing $18 \mathrm{mM}$ citric acid and $60 \mathrm{mM}$ dibasic sodium phosphate. Subsequently, the cell walls were treated with chitinase C (InterSpex Products) for $3 \mathrm{~h}$ at $37^{\circ} \mathrm{C}$. The level of chitin was measured with Ehrlich's reagent as described (Reissig et al., 1955).

Microscopic analysis of mycelia. T. reesei transformants and control strains were harvested by centrifugation, washed twice with sterile water, resuspended in warm $1.5 \%$ agarose (A-5030 Type IX from Sigma), allowed to cool and observed under a Nicon Eclipse E 6800 fluorescence microscope. The hyphae diameter and distances between septa were calculated from about one hundred pictures of each strain using Lucia G program.

\section{RESULTS}

\section{Disruption of the pmt1 gene in $T$. reesei}

T. reesei TU-6, a spyr4 mutant of $T$. reesei QM9414, was transformed with a DNA fragment of about $6.5 \mathrm{~kb}$ containing $T$. reesei pyr4 gene flanked with pmt1 sequences, as described in Methods. Prototrophic transformants were selected and isolated by three rounds of transfer from selective to nonselective medium and screened by Southern blotting for the genomic copy of pmt1. To this aim genomic DNA of the transformants and the control strain was digested with $P v u \mathrm{II} / \mathrm{XhoI}$ and hybridized with a pmt1 probe cut out from $\mathrm{pGEM}$ with the same restriction enzymes. The pmt1 gene contains one restriction site for each of the enzymes, so its intact copy should yield a $1.98 \mathrm{~kb}$ fragment hybridizing with the probe. Since T. reesei pyr4 has many PvuII and XhoI restriction sites, DNA obtained from the disruptants gave two fragments of 1.35 and $1.26 \mathrm{~kb}$ hybridizing with the pmt1 probe (Fig. 1A, B).

Effect of pmt1 gene disruption on the total activity of protein $O$-mannosyltransferases

Protein O-mannosyltransferase I (PMTI protein) encoded by the pmt1 gene catalyzes transfer of the mannosyl residue from dolichyl phosphate mannose (DPM) to a serine or threonine $\mathrm{OH}$ group in the protein. To determined the influence of pmt1 disruption on the total activity of direct O-glycosylation we measured the combined activity of all PMT proteins. The experiment revealed a significant decrease of the total activity of protein $O$-mannosyltransferases, to $67 \%$ of the control value (Fig. 1C).

Effect of the lower activity of protein O-mannosyltransferases on the growth of Trichoderma, protein secretion and glycosylation of secreted proteins

Trichoderma strains were cultivated on agar plates containing MM medium with glucose or lactose as a carbon source, supplemented with $1 \mathrm{M}$ sorbitol or $0.6 \mathrm{M} \mathrm{KCl}$ as osmotic stabilizers (Oka et al., 2004). Every $24 \mathrm{~h}$ the diameter of the colony was measured and the results are presented as millilitre of growth per hour (Table 1). Colony growth of the strain carrying disruption of the pmt1 gene was very slow and reached $17 \%$ of the control when cultivated on the MM medium without osmotic stabilizers. Addition of $1 \mathrm{M}$ sorbitol or $0.6 \mathrm{M} \mathrm{KCl}$ to the cultivation medium inhibited growth of the control strain and the level of inhibition depended on the carbon source. The most pronounced effect on growth of the control strain was found on lactose-containing medium supplemented with sorbitol. An opposite effect was observed for the pmt1 disruptant which grew nearly twice better with osmotic stabilization, nonetheless, the growth still remained slower compared to the growth of the control strain on medium without supplements.

We also examined growth of the strains in liquid MM medium with lactose and it turned out that the strain MJK1/07 carrying pmt1 disruption was not able to growth without osmotic stabilization. Therefore, Trichoderma strains were cultivated with $1 \mathrm{M}$ sorbitol and every $24 \mathrm{~h}$ mycelia were collected and growth of the strains was presented as an increase of dry mass of mycelia during cultivation (Fig. 2). Rather unexpectedly the pmt1 disruptant turned out to grow better than the control strain. At the same time we measured the amount of proteins liberated to the cultivation medium during $288 \mathrm{~h}$ of cultivation and found that the strain carrying disruption of the pmt1 gene secreted less protein compared to the control strain (Fig. 3).

Since we found that the activity of protein $O$-mannosyltransferases in the examined strain was decreased we expected changes in the intensity of O-glycosylation of secreted protein. Since changes in O-glycosylation could influence $\mathrm{N}$-glycosylation (Ecker et al., 2003) we characterized the amount of both $\mathrm{O}-$ and $\mathrm{N}$-linked sugars bound to the secreted proteins. To this end, the proteins from the cultivation medium were isolated and after mild alkaline 
A

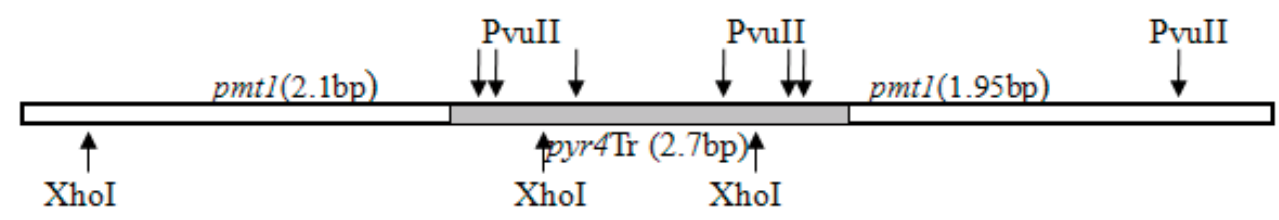

B

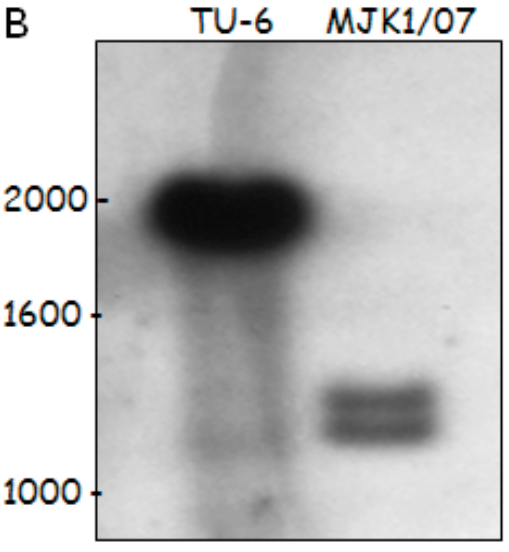

C

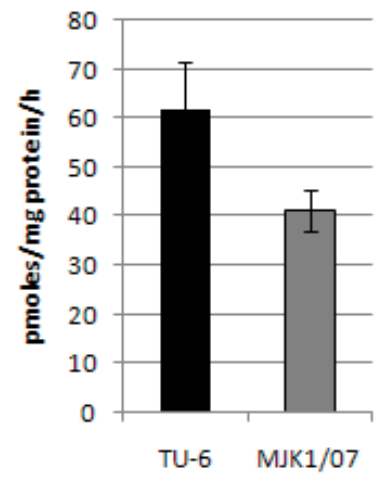

Figure 1. Poproszę o wspólny tytuł

A. Schematic presentation of DNA fragment used for pmt1 gene disruption in T. reesei TU-6. Arrows point at restriction sites for PvuII and XhoI. B. Southern blot analysis of PvuII and XhoI digested total DNA of parental strain (TU-6) and the pmt1 disrupted strain (MJK1/07). C. Total activity of protein O-mannosyltransferases in membrane fraction from T. reesei strain carrying disruption of pmt1 gene (MJK1/07) in comparison to the host strain TU-6. Strains were cultivated for $168 \mathrm{~h}$ in MM medium with lactose supplemented with $1 \mathrm{M}$ sorbitol. The data are presented as mean \pm standard deviation from three separate cultures.

hydrolysis the amount of liberated O-linked sugars was measured (Table 2).

We found that the amount of O-linked carbohydrates bound to the secreted proteins was only $14 \%$ lower in the strain carrying disruption of the pmt1 gene compared to the control strain. An assay of Nlinked carbohydrates revealed only $5 \%$ less of these sugars bound to the secreted proteins. Student's $t$-test revealed that the differences were not statistically sig-

Table 1. Growth rate of T. reesei strain MJK1/07 carrying disruption of the pmt1 gene and the parental strain TU6.

\begin{tabular}{lll}
\hline Medium & TU-6 & MJK1/07 \\
\hline MML & $0.40 \pm 0.017$ & $0.07 \pm 0.005$ \\
MML+1 M sorbitol & $0.16 \pm 0.011$ & $0.11 \pm 0.005$ \\
MML+0.6 M KCl & $0.25 \pm 0.012$ & $0.11 \pm 0.007$ \\
MMG & $0.42 \pm 0.022$ & $0.07 \pm 0.007$ \\
MMG+1 M sorbitol & $0.30 \pm 0.019$ & $0.12 \pm 0.008$ \\
MMG+0.6 MKCl & $0.33 \pm 0.016$ & $0.12 \pm 0.009$ \\
MMG+ Calcofluor white & $0.41 \pm 0.015$ & not growing \\
\hline
\end{tabular}

Growth values are in $\mathrm{mm} \mathrm{h}^{-1}$. The data are presented as mean \pm standard deviation from six separate cultures. MMG and MML, minimal medium with glucose or lactose as a carbon source. nificant. On the other hand, we measured activity of $\mathrm{N}$-acetylglucosamine transferase, the first enzyme in the N-glycosylation pathway and found it $78 \%$ more active compared to the control strain (Fig. 4).

Influence of the lower activity of $O$-mannosyltransferases on the cell wall of the mutant

The strain carrying disruption of the pmt1 gene did not grow in liquid medium without sorbi-

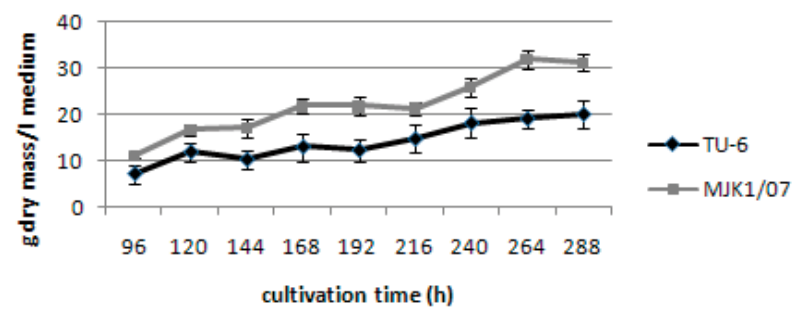

Figure 2. Growth of $T$. reesei strain carrying disruption of pmt1 gene and the control strain cultivated in MM liquid medium with lactose supplemented with $1 \mathrm{M}$ sorbitol.

The data are presented as mean \pm standard deviation from five separate cultures. 


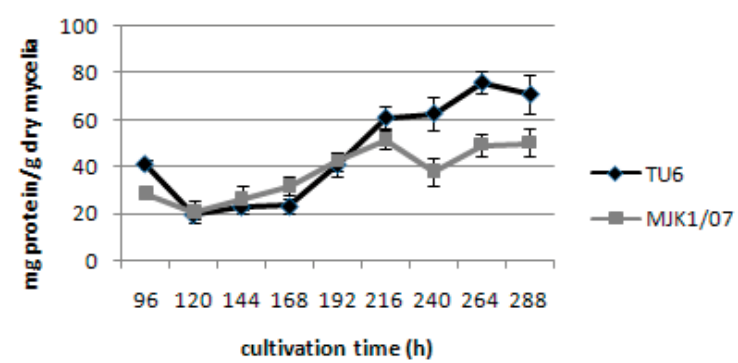

Figure 3. Amount of secreted proteins in cultivation medium from MJK1/07 strain carrying disruption of pmt1 gene and its host TU-6 strain.

Strains were cultivated in MM with lactose supplemented with $1 \mathrm{M}$ sorbitol. The data are presented as mean \pm standard deviation from five separate cultures.

tol, which suggested that the decreased activity of the PMTI O-mannosyltransferase could alter the composition of the cell wall in this strain. Moreover, the pmt1 mutant did not grow in the presence of the antifungal agent Calcofluor white while growth of the control strain was not inhibited in these conditions (Table 1).

To study the results of the disruption of the pmt1 gene on the cell wall composition the mutant strain and the control were cultivated in media with an osmotic stabilizer, the cell wall was isolated and the content of glucans and chitin measured. The level of alkali-soluble $\beta$-(1,6)glucan observed for the MJK1/07 strain carrying disruption of the pmt1 gene was decreased to $89 \%$ of the control value (Table 3 ). No detectable amount of $\beta-(1,3)$ glucan or alkali-insoluble $\beta-(1,6)$ glucan was found in either strain. Moreover, an assay of the chitin content in the cell wall revealed no differences between the transformant and the control.

\section{Microscopic analysis of mycelia}

Our T. reesei mutant exhibited significant changes in the composition of its cell wall. Since a weak cell wall could influence the structure of mycelia we examined our strain under a phase-contrast microscope and measured the diameter of hyphae and the distance between septa using the Lucia G program. One-hundred pictures of transformant and control were analyzed, and we found that the

Table 2. Carbohydrates bound to the secreted proteins in the pmt1 disrupted strain MJK1/07 compared to the host strainTU-6

\begin{tabular}{lll}
\hline & $\mu$ g sugar/mg protein & \\
\hline Strain & O-linked & N-linked \\
TU-6 & $4.64 \pm 0.91$ & $77.63 \pm 6.92$ \\
MJK1/07 & $4.00 \pm 0.76$ & $73.63 \pm 6.92$ \\
\hline
\end{tabular}

The data are presented as mean \pm standard deviation from three separate cultures.

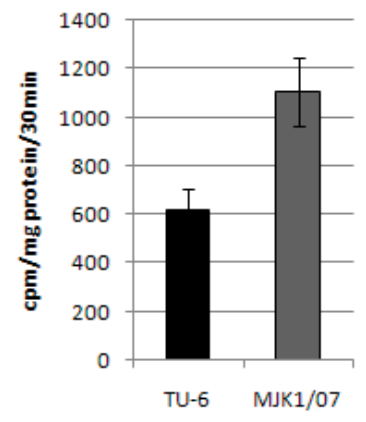

Figure 4. Activity of $\mathrm{N}$-acetylglucosamine transferase in membrane fraction from $T$. reesei strain with disruption of pmt1 gene (MJK1/07) in comparison to the host strain TU-6.

Strains were cultivated for $168 \mathrm{~h}$ in $\mathrm{MM}$ medium with lactose supplemented with $1 \mathrm{M}$ sorbitol. The data are presented as mean \pm standard deviation from three separate cultures.

distance between septa was more than twice longer in the disruptant MJK1/07 compared to the control (Table 4). Moreover, mycelia of the strain bearing disruption of the pmt1 gene were slightly narrower compared to the control.

\section{DISCUSSION}

Our earlier studies showed that elevation of DPM synthase, guanyltransferase or cis-prenyltransferase activity in Trichoderma or Aspergillus caused significant changes in the activity of other enzymes engaged in the O-glycosylation pathway and altered protein secretion or glycosylation of secreted proteins (Zakrzewska et al., 2003b; Perlińska-Lenart et al., 2005; 2006a; 2006b). This study concentrates on protein O-mannosyltransferase I (PMTI) catalyzing the direct transfer of mannosyl residue to proteins.

Our results showed that disruption of the pmt1 gene encoding PMTI protein led to a significant decrease in the total activity of protein O-mannosyltransferases. Simultaneously with the lower activity of protein $O$-mannosyltransferases in the strain bearing disruption of the pmt1 gene, we found so profound alteration of the cell wall composition

Table 3. Cell wall composition of $T$. reesei strains carrying pmt1 disruption (MJK1/07) compared to the parental strain TU-6

\begin{tabular}{lll}
\hline \multicolumn{3}{c}{ Amount of carbohydrate $(\mu \mathrm{g} / \mathrm{mg}$ dry cell wall) } \\
\hline Strain & Alkali soluble $\beta-(1,6)$ glucan & Chitin \\
& $149.54 \pm 11.32$ & $2.74 \pm 0.48$ \\
TU-6 & $133.28 \pm 13.25$ & $2.93 \pm 0.51$ \\
\hline
\end{tabular}

The data are presented as mean \pm standard deviation from three separate cultures. The cell walls were isolated from the strains after $168 \mathrm{~h}$ of growth in lactose MM medium with sorbitol. 
Table 4. Hyphae diameter and distance between septa in T. reesei strains carrying pmt1 disruption (MJK1/07) compared to the parental strains TU-6

\begin{tabular}{lll}
\hline Strain & $\begin{array}{l}\text { Hyphae diameter } \\
(\mu \mathrm{m})\end{array}$ & $\begin{array}{l}\text { Distance between septa } \\
(\mu \mathrm{m})\end{array}$ \\
\hline TU-6 & $3.70 \pm 0.51$ & $21.98 \pm 4.21$ \\
MJK1/07 & $3.37 \pm 0.48$ & $54.40 \pm 8.44$ \\
\hline
\end{tabular}

The data are mean \pm standard deviation from one hundred measurements.

that this strain could not grow in a liquid medium without sorbitol. The strain was able to grow very slowly on agar plates without osmotic stabilizers, however, osmotic stabilization by $1 \mathrm{M}$ sorbitol or $0.6 \mathrm{M} \mathrm{KCl}$ clearly enhanced its growth. Furthermore, the pmt1 mutant was sensitive to Calcofluor white which is known to be adsorbed on cell wall polysaccharides and exhibits an antifungal effect.

In $A$. nidulans, disruption of the $p m t A$ gene resulted in a more than two-fold decrease in growth rate in liquid medium compared to the wild-type strain and the growth of both strains became similar after supplementation of the medium with an osmotic stabilizer (Oka et al., 2004). These data suggested that changes in the cell wall of the $A$. nidulans pmt $A$ disruptant were not as dramatic as those found in the Trichoderma MJK1/07 strain. The difference could be caused by an increased production of chitin in the Aspergillus pmtA strain compared to the control, which was not observed in the Trichoderma disruptant. The cell wall of Aspergillus was rescued by induction of a cell wall compensatory mechanism manifested by higher production of chitin (Oka et al., 2004; 2005). To induce this mechanism, sensor proteins present in the cell wall detect and transmit the cell wall status to a signaling pathway comprised of a cascade of MAP kinases (Levin, 2005). The extracellular domains of these sensors are highly O-mannosylated, and their limited mannosylation could result in a loss of function (Lommel et al., 2004). Since the PMT proteins are substrate-specific, it is possible that the PMTA protein from Aspergillus and the PMTI protein from Trichoderma differ in their substrate specificity and that PMTI from Trichoderma normally glycosylates cell wall sensors, in contrast to PMTA which glycosylates other substrates.

The Trichoderma PMTI protein, although structurally similar to $S$. cerevisiae Pmt4p, functionally could replace the Pmt2 protein from S. cerevisiae (Zakrzewska et al., 2003a) and is a homolog of S. pombe Oma2p. It has been shown that in $S$. pombe Oma2p takes part in glycosylation of the cell wall sensor protein Wsc1p and disruption of the oma2 gene is lethal (Willer et al., 2005).

Analysis of the cell wall composition of our transformants showed that the level of $\beta$ - $(1,3)$ glucan and alkali-insoluble $\beta-(1,6)$ glucan was not detectable and we could only measure the amount of alkalisoluble $\beta-(1,6)$ glucan and chitin.

Furthermore, microscopic studies of our strains showed a significant decrease in the number of septa in the mycelia of the mutant. The troubles with septa formation could be connected with the lack of $\beta$-(1,3)glucan. It has been reported that in S. pombe disruption of $\beta$-(1,3)glucan synthase gene (bgs1) resulting in a decreased amount of $\beta$-(1,3)glucan causes defects in septa formation (Carlos et al., 2007).

On the other hand, the troubles with the synthesis of cell wall components could be a result of cultivation of the strains in a medium supplemented with sorbitol. A similar effect was observed for $\mathrm{Neu}$ rospora crassa cultivated with an addition of sorbitol, where the cell wall components were synthesized in a limited amount and the activity of $\beta-(1,3)$ glucan synthase was decreased. In consequence, the fungus grew solely in the form of protoplasts (da Silva et al., 1994).

In this study we also examined the influence of a decreased activity of protein O-mannosyltransferases on the secretion of proteins and their glycosylation. We found that the strain carrying disruption of the pmt1 gene secreted a lower amount of proteins compared to the control. A lower secretion was also observed for a Hansenula polymorpha pmt mutant, however, only secretion of O-mannosylated proteins was inhibited, as shown for chitinase which was secreted in a very limited amount (Agaphonov et al., 2005). Invertase or heterologously expressed human urinary type plasminogen activator, which are normally $\mathrm{N}$-glycosylated, were secreted in elevated amounts, although they were unglycosylated.

In $T$. reesei the majority of secretory proteins are highly glycosylated with both $\mathrm{N}$ - and O-linked glycans (Palamarczyk et al., 1998). The lack of activity of the PMTI protein O-mannosyltransferase in the strain carrying the pmt1 disruption only slightly decreased or even not altered O- and N-glycosylation of secreted proteins. These results suggest that the protein $O$-mannosyltransferase PMTI only marginally participates in glycosylation of secreted proteins. On the other hand, the activity of $\mathrm{N}$ acetylglucosamine transferase was enhanced in the pmt1 disruptant suggesting that N-glycosylation of some proteins, although not the secretory ones, should be stimulated in this strain.

It has been shown for an $S$. cerevisiae pmt4 $\Delta$ mutant that a lack of O-linked sugar bound to the serine or threonine in the vicinity of the $\mathrm{N}$-glycosylation site enables $\mathrm{N}$-glycosylation, while in the wild type strain when the O-glycosylation site is occupied the $\mathrm{N}$-glycosylation site remains not glycosylated (Ecker et al., 2003). 
In the present paper we showed the consequences of a lack of the PMTI protein O-mannosytransferase on the survival of Trichoderma cells, protein glycosylation and secretion and on the cell wall formation. We also showed that PMTI protein $\mathrm{O}$-mannosyltransferase did not take part in the Oglycosylation of the secreted proteins. Moreover, the increased activity of $\mathrm{N}$-acetylglucosamine transferase observed in the pmt1 disruptant could confirm an interdependence between protein $\mathrm{O}-$ and $\mathrm{N}$-glycosylation.

\section{Acknowledgements}

We wish to thank Prof. Robert Mach from Technical University of Vienna for the pGF1plasmid.

This work was partially supported by the State Committee for Scientific Research (KBN, Poland), grant No. 6P04B00621 to J.S.K.

\section{REFERENCES}

Agaphonov MO, Sokolov S, Romanova NV, Sohn J, Kim SY, Kalebina TS, Choi ES, Ter-Avanesyan MD (2005) Mutation of the protein-O-mannosyltransferase enhances secretion of the human urokinase-type plasminogen activator in Hansenula polymorpha. Yeast 22: 1037-1047.

Carlos J, Cortes G, Konomi M, Martins IM, Munoz J, Moreno B, Osumi M, Duran A, Ribas JC (2007) The $(1,3) \beta$-D-glucan synthase subunit $B g s 1 \mathrm{p}$ is responsible for the fission yeast primary septum formation. Mol Microbiol 65: 201-217.

da-Silva MM, Polizeli ML, Jorge JA, Terenzi HF (1994) Cell wall deficiency in "slime" strains of Neurospora crassa: osmotic inhibition of cell wall synthesis and beta-Dglucan synthase activity. Braz J Biol Res 27: 2843-2857.

Dubois M, Gilles K, Hamilton JK, Rebers PA, Smith F (1956) Colorimetric method for determination of sugar and related substrates. Anal Biochem 28: 350-356.

Ecker M, Mrsa V, Hagen I, Deutzmann R, Strahl S, Tanner W (2003) O-mannosylation precedes and potentially controls the N-glycosylation of a yeast cell wall glycoprotein. EMBO Rep 4: 628-632.

Gentzsch M, Tanner W (1996) The PMT gene family: protein O-glycosylation in Saccharomyces cerevisiae is vital. EMBO J 15: 5752-5759.

Gentzsch M, Tanner W (1997) Protein-O-glycosylation in yeast: protein-specific mannosyltransferases. Glycobiology 7: 481-486.

Górka-Nieć W, Bańkowska R, Palamarczyk G, Krotkiewski H, Kruszewska JS (2007) Protein glycosylation in pmt mutants of Saccharomyces cerevisiae. Influence of heterologously expressed cellobiohydrolase II of Trichoderma reesei and elevated levels of GDP-mannose and cisprenyltransferase activity. Biochim Biophys Acta 1770: 774-780.

Gruber F, Visser J, Kubicek CP, de Graaff LH (1990) Cloning of the Trichoderma reesei pyrG gene and its use as a homologous marker for a high-frequency transformation system. Curr Genet 18: 447-451.

Harman GE, Kubicek CP (1998) Enzymes, biocontrol and commercial applications. In Trichoderma and Glocladi- um. Harman EG, Kubicek CP, eds, vol. 2, pp 129-163. Taylor and Francis Ltd., London.

Kruszewska J, Messner R, Kubicek CP, Palamarczyk G (1989) O-glycosylation of proteins by membrane fraction of Trichoderma reesei QM9414. J Gen Microbiol 135: 301-307.

Kruszewska J, Butterweck AH, Kurzątkowski W, Migdalski A, Kubicek CP, Palamarczyk G (1999) Overexpression of the Saccharomyces cerevisiae mannosylphosphodolichol synthase - encoding gene in Trichoderma reesei results in an increased level of protein secretion and abnormal cell ultrastructure. Appl Environm Microbiol 65: 2382-2387.

Levin DE (2005) Cell wall integrity signaling in Saccharomyces cerevisiae. Microbiol Mol Biol Rev 69: 262-291.

Lommel M, Bognat M, Strahl S (2004) Aberrant processing of the WSC family and Mid2p cell surface sensors in cell death of Saccharomyces cerevisiae O-mannosylation mutants. Mol Cell Biol 24: 46-57.

Lowry OH, Rosebrough NJ, Farr AL, Randall RJ (1951) Protein measurement with the Folin phenol reagent. $J$ Biol Chem 193: 265-275.

Nemcovic M, Farkas V (2001) Cell wall composition and polysaccharide synthase activity changes following photoinduction in Trichoderma viride. Acta Biol Hung 52: 281-288.

Oka T, Hamaguchi T, Sameshima Y, Goto M, Furukawa K (2004) Molecular characterization of protein O-mannosylation and its involvement in cell-wall synthesis in Aspergillus nidulans. Microbiol 150: 1973-1982.

Oka T, Sameshima Y, Koga T, Kim H, Goto M, Furukawa K (2005) Protein O-mannosyltransferase A of Aspergillus awamori is involved in O-mannosylation of glucoamylase I. Microbiol 151: 3657-3667.

Palamarczyk G, Hemming FW (1975) The formation of mono- $N$-acetylhexosamine derivatives of dolichol phosphate by pig liver microsomal fractions. Biochem J 148: 243-251.

Palamarczyk G, Maras M, Contreras R, Kruszewska J (1998) Protein secretion and glycosylation in Trichoderma. In Trichoderma and Glocladium. Kubicek CP, Harman GE, eds, vol 1, pp 121-138. Taylor and Francis Ltd, London.

Perlińska-Lenart U, Kurzątkowski W, Janas P, Kopińska A, Palamarczyk G, Kruszewska JS (2005) Protein production and secretion in an Aspergillus nidulans mutant impaired in glycosylation. Acta Biochim Polon 52: 195-205.

Perlińska-Lenart U, Bańkowska R, Palamarczyk G, Kruszewska JS (2006a) Overexpression of the Saccharomyces cerevisiae RER2 gene in Trichoderma reesei affects dolichol dependent enzymes and protein glycosylation. Fungal Genet Biol 43: 422-429.

Perlińska-Lenart U, Orłowski J, Laudy AE, Zdebska E, Palamarczyk G, Kruszewska JS (2006b) Glycoprotein hypersecretion alters the cell wall in Trichoderma reesei strains expressing the Saccharomyces cerevisiae dolichylphosphate mannose synthase gene. Appl Environ Microbiol 72: 7778-7784.

Pless DD, Palamarczyk G (1987) Comparison of polyprenol derivatives in yeast glycosyl transfer reactions. Biochim Biophys Acta 529: 21-28.

Reissig JL, Storminger JL, Leloir LF (1955) A modified colorimetric method for the estimation of $\mathrm{N}$-acetylamino sugars. J Biol Chem 217: 959-966.

Sambrook J, Fritsch EF, Maniatis T (1989) Molecular cloning: a laboratory manual, 2nd edn, vol 1, pp 7.37-7.52. Cold Spring Harbor Laboratory, Cold Spring Harbor, N.Y. 
Sharma CB, Babczinski P, Lehle L, Tanner W (1974) The role of dolicholmonophosphate in glycoprotein biosynthesis in Saccharomyces cerevisiae. Eur J Biochem 46: 35-41.

Strahl-Bolsinger S, Gentzsch M, Tanner W (1999) Protein O-mannosylation. Biochim Biophys Acta 1426: 297-307.

Willer T, Brandl M, Sipiczki M, Strahl S (2005) Protein O-mannosylation is crucial for cell wall integrity, septation and viability in fission yeast. Mol Microbiol 57: 156-170.

Yanish-Perron C, Vieira J, Messing J (1985) Improved M13 phage cloning vectors and host strains: nucleotide sequences of the M13mp18 and pUC 19 vectors. Gene 33: 103-119.
Zakrzewska A, Migdalski A, Saloheimo M, Penttilä ME, Palamarczyk G, Kruszewska JS (2003a) cDNA encoding protein O-mannosyltransferase from the filamentous fungus Trichoderma reesei; functional equivalence to Saccharomyces cerevisiae PMT2. Curr Genet 43: 11-16.

Zakrzewska A, Palamarczyk G, Krotkiewski H, Zdebska E, Saloheimo M, Penttilä M, Kruszewska JS (2003b) Overexpression of the gene encoding GTP-mannose-1-phosphate guanyltransferase, mpg1, increases cellular GDPmannose levels and protein mannosylation in Trichoderma reesei. Appl Environ Microbiol 69: 4383-4389. 